\title{
Problems of Bibliographical Control for an Area Research Program
}

Miss Herrick is associate librarian, and $\mathrm{Dr}$. Hill is administrative assistant and research associate with the African Research Studies Program, Boston University.

$\mathrm{T}$ HE DEVELOPMENT OF an inter-disciplinary area program, particularly if the area is as generally unfamiliar as Africa, brings out in bold relief the strong dependence of a university on its library resources. To single out for discussion the dependence upon its library of a university program of any type suggests the level of absurdity not usually rewarded by publication. However, it is precisely this regularity of expectancy and rewards which has dulled our perception as to its necessity and the intricate mechanism involved in achieving this relationship.

All institutions function on the basis of familiar patterns and established routines; this is no less true with university-library interaction. Scholars and would-be scholars legitimately expect a "good" library to purchase and house the required literature in a given field of interest. Librarians conversely anticipate routine request for available material on the part of the scholars and aspiring scholars. As a rule such mutual expectations are met-at least to the extent of maintaining the function of the institution. Nor is there a breakdown in the process should a department introduce a new course emphasizing familiar but previously unwanted materials. A shift from Bacon to Joyce merely extends the library facilities and perhaps temporarily inactivates certain others. The obligation of introducing new courses to prepare students for the newer fields of study such as electronics or psychosomatic medicine may involve, perhaps, some re-evaluation, some displacement and disruption in the smooth routine of libraryfaculty interaction, but, on the whole, if funds are available the process is gradual and developmental, affecting perhaps only one or rarely more than three members of a department.

Imagine, however, the situation of a group of departments having, it is true, a common interest in a problem or problems, but lacking the familiar instruments of working together, lacking all too frequently more than the minimum understanding of one another's orientations, techniques, basic sources, et cetera, attempting to study Africa and expecting the familiar assistance from the library. Initially there emerges the problem of the accessibility of such material, which, while not necessarily vast in amount, is scattered throughout the world. The factors of location, communication, distance, even changes of personel must be overcome.

To be more specific, our contact with Africa, though extending back to the 17 th and 18 th centuries, is neither broad nor productive in a literary way. Most of the European powers in their 500 years or more of African contact have amassed a wide range of publications in many different languages and now located in many different places. Aside from these valuable historical sources, an African program must expect its library to possess the data now regularly produced by the rapidly growing number of research institutes located in Europe, in the United Kingdom and in Africa. As a general rule 
the institutes in Africa are considerably understaffed and frequently they lack the facilities systematically to publicize or circularize much of their data. To some extent changes for the better are indicated, but there is still the real problem of establishing for these institutes the strength they will need to develop them as sources of research.

As most of Africa is, or has been, under the jurisdiction of European powers, much valuable information is in the form of official reports and is available only through the official governments and government offices concerned. The familiar bureaucratic headaches become "the order of the day."

Indeed, far more than general library efficiency can absorb, each order could require an independent contact. The usually reliable dealers on whom any good library must depend are less useful for these materials because they have not in the past had the need to develop contacts with these remote sources. While in routine acquisitions a dealer could fulfill with some rapidity all the usual subject requests, now the library staff must frequently initiate and maintain numerous independent contacts. And this does not exhaust the problem. The stimulus of attempting to cover the needs of a rapidly changing society constantly creates new journals and special reports and eliminates the need for others. The librarians' expectation for continuity in the publications of serials is frequently frustrated.

Material once received, the problem of useful and permanent cataloging emerges. How most effectively can these new materials be fitted into established headings? How can the loss of valuable hidden contributions be further avoided without recourse to minute subject analysis? How can the larger amounts of so-called fugitive materials-pamphlets, speeches, short reports and government documents - be made accessible for ready reference? These are but a few of the problems of bibliographical control that occur in the development of a special area program. Present methods of subject analysis can provide good correlation between a book collection and the traditional departmental organization in a university. In theory, all facets of inter-relationships can be expressed, according to Ranganathan and Taube. In fact, however, we do not have these methods available for use.

The area program, as it orients all knowledge about the spatial unit, presents a wider and more basic challenge in providing for adequate and economical subject analysis than we have had heretofore. The publications are dispersed throughout history, anthropology, sociology, religion and the arts. Wisely, the area specialists at Boston University rejected the chimera of the development of a special classification scheme to keep all the materials together. Enticing as this appears at first glance, if put into operation it would remove all the value that might be gained by the presence of material for comparative studies. It would also segregate a large amount of information that could be used by students in other programs.

The present day philosophy of book classification supports the principle both of "broad" and "close" classification. Whatever method is followed, subject placement of material is paramount. Because book classifications are necessarily linear, the subject catalog is the only source for the expression of multi-subject coverage of a volume. The basic principle of primary entry under specific subject is usually accepted as it is in classification. There is, of course, representation of geographical areas, but when the subject transcends geographical or political limits these areas are subordinate to the subject. For example, religion, art and philosophy are subdivided geographically in traditional subject catalogs. Thus while political history of the Gold Coast is found in 
a subject catalog under Gold Coast-Politics and Government, the education of the Africans in the Gold Coast will be found under Education-Gold Coast.

The high costs of providing detailed analysis of materials [from two to five dollars per title] makes it almost impossible for the average library to satisfy fully the demands of either the geographical area specialist or the subject specialist. The remainder of this paper will present a description of the steps taken in one medium-sized university library system to provide a partial solution for the area specialist.

The African Studies Program was instituted in the spring of 1953 but its work was not organized until the director arrived at the start of the 1953/54 academic year. It is, therefore, in a beginning stage of operation and its policies and lines of direction barely formulated. With a research staff busily concerned with setting up contacts abroad, and drawing up courses and areas of study at home, there is little time to work with the library on individual items as they come in. Almost daily conferences for the first few weeks helped to establish mutually agreeable means of communication, understanding of joint problems and the general type of treatment required for books, pamphlets and serials. We cannot now, nor at any foreseeable future time, prepare the depth of subject indexing to the collection that is possible in other fields, such as provided by $C$ hemical $A$ bstracts. We are, however, working toward an expansion of the ordinary procedures used in our general cataloging. All books and serials are treated as any other library materials. They would not, of course, ordinarily receive a two way approach of entry both under place and under topic. True, there are possibilities of a chain connection by "see references." There could be cards in the subject catalog under Africa saying Africa-Birds-see Birds-Africa; Africa-Art-see Art; So- cial insurance-see Insurance, SocialAfrica; and for all the other subject aspects that are not usually represented directly under the name of a geographical area. This is cumbersome, but to provide duplicate entries under both Africa and the topic would be prohibitively expensive in labor, materials and in space requirements in a general library catalog. At Northwestern University where a program of African studies has been in existence since 1948/49 there is a separate author and area catalog of this material. The statement is made that "it is planned to have a subject-matter classification catalog made as soon as the necessary additional cards can be obtained and sorted."1 Although it happens that Boston University's subject catalog is in a classified rather than an alphabetical arrangement the problem of subject analysis is the same. The solution being tested is a simple one. It is what we have chosen to call an "African Oriented Index" to our collection. Here topics-i.e., Tribes, Cities, Regions, as well as general subject-are listed in alphabetical order subordinated to Africa, and each time a new aspect is recorded the list is annotated. It does not list titles, but only records location symbols as they appear in the classified subject catalog. Thus it does not require any large expenditure to accomplish its purpose. Under Africa at present we have over five hundred separate topics listed with their appropriate number symbols. A reference to the catalog under any one of these shows at once the items that refer wholly or in part to that topic. To prevent this index becoming unwieldy in such areas as Ethnology (where almost every part of Africa is represented), we affix a note indicating that there is general area coverage here. This allows us to omit the listing of separate colonies and countries, but indicates to the student he can

1 Northwestern University. Program of African studies, I 949/53. (Evanston, Ill.: I953, p. II). 
be sure of finding something on each place. In other topics, however, where there is not as yet any extensive collection, such as Taxation, the exact areas represented are listed. The reason for this is two-fold, it serves as a guide to the student exploring the field for a topic to allow him to judge if it offers enough material for study; and it also serves as a guide to the faculty showing the limitations of the holdings. When the statement of extensive coverage is given, as under Ethnology, the problem of acquisition of more materials is only one of continued steady growth, but if a topic shows sparse or spotty representation it may draw attention to the need for stepped-up acquisitions or possibly the development of a research study to help provide better coverage. A brief excerpt from this index is given below:

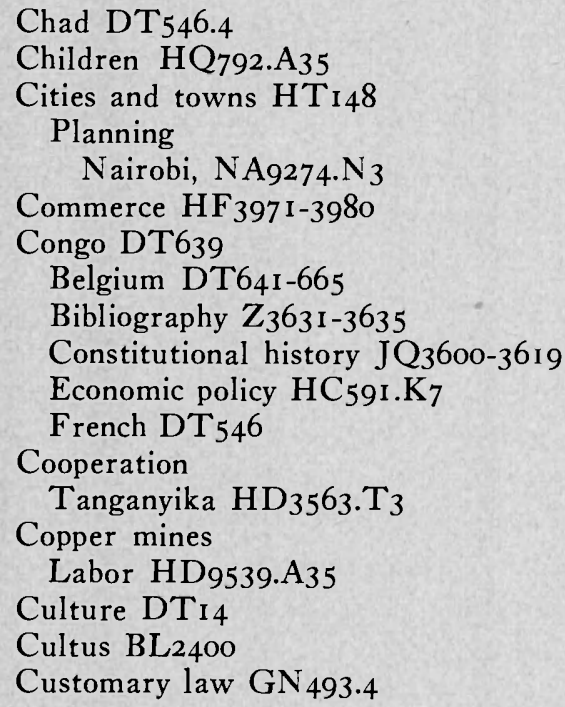

In addition to the cataloged collection there are about five hundred pamphlets not at present separately cataloged. They include material more valuable than that usually kept in a vertical file. Much of it is from the offices of the colonial governments, reports of field studies or brief monographic studies. The pamphlet collection is arranged on the basis of area and is only represented in the card catalog by general refer- ences to these areas, indicating there is a collection of pamphlets available. In ordering pamphlet materials a four-part multiple form is used. One of these forms goes to the dealer, and when the item is received the others accompany it to the cataloging department. Here the area number, such as DT5 I (Gold Coast) is put on the slips and on the pamphlet. The remaining slips are distributed, one to the director of the program, two to a separate pamphlet cata$\log$. This pamphlet is kept with the collection and serves as an index to it. It is in two files, the one by number serves as shelflist, and the other is an alphabetical subject index. Some of the pamphlets do not require representation in the second file; for example, a general study of Nigeria is sufficiently available with a slip in the number file, but if the study is concerned primarily with the cooperatives in that area it will also be represented in the subject file. These slips are used just as they come from the order department; they usually have an acceptable bibliographical form of entry but no long reach is made to identify them or is any attempt generally made to edit them to bring them in line with official headings. The file is only a finding device, kept as simple and as inexpensive as possible. In this way we are able to provide workable access to this collection while it is reasonably small. As it grows we expect to incorporate some of the monographs into the book collection. When it becomes apparent that we are receiving a serial regularly, it is removed and separately cataloged. Some material, as it becomes outdated, may be removed to "historical files," withdrawn or stored as the program director recommends.

The next step is a joint one, with the program staff bearing the major part of the work load. The staff plans to explore methods by which a subject specialist from the program might do further subject analysis in certain areas and with selected parts 
tof the library collection. Every attempt will be made to keep the terminology and form of this subject analysis in line with cataloging principles wherever possible. The responsibility of the library will be to follow the work of the staff member, to confer on choice of terms and to provide links from the subject catalog to the analysis file, or if the analytics are put into the central catalog, to see that they are edited and integrated into the main subject index.

We feel that a recognition of the complexity of the problem at hand is crucial to its solution-though not its solution. When several specialists have an important stake in the successful solution of a problem, a meeting of the minds, a willingness to understand one another's difficulties, to permit a flexibility in established procedures all combine to set the stage for this vitally important operation. It is no longer feasible merely to entertain expectations. Discussions around a conference table from time to time between library staff and program staff can do more than anything else to maintain the important respect and cooperation which will ensure the success of the program and the growth of the library as the repository of its major collections of research materials.

\section{American University Libraries, 1955-2005}

\section{(Continued from page 29o)}

but they quite probably will still be so expensive in 2005 that only a few libraries will be able to afford them; (3) there may be a limit to the amount of speed and efficiency faculty members will accept.

Librarians will not approve of this apparent backwardness on the part of scholars, but it will be the result of habits of thought which are hard to change. If a man is going to spend a period of six months to six years in producing a piece of research, it cannot make much difference to him if the librarian is able to assemble and to present him with the materials he needs within a period of two days instead of a period of two weeks.

It might be worthwhile to turn to some of the less mechanical weapons employed by university library staffs in fighting the battle for bibliographical control of facts and ideas. If card catalogs grow much in size, they will surely be broken in pieces; some have already lost sizable chunks. Will these breaks follow subject lines, format or language lines, or lines that divide the books according to date of publication? Will the catalog some day describe only those materials not described in printed bibliographies? Guesses about the future of the weapons to be used in bibliographical warfare could easily make a book in themselves.

The present discussion should come to a stop before it, too, becomes a book. Let it close, however, with the expression of a hope that librarians will not allow their guessing about the future to stop as books do, but will extend it indefinitely, in the manner of the healthier serials. 